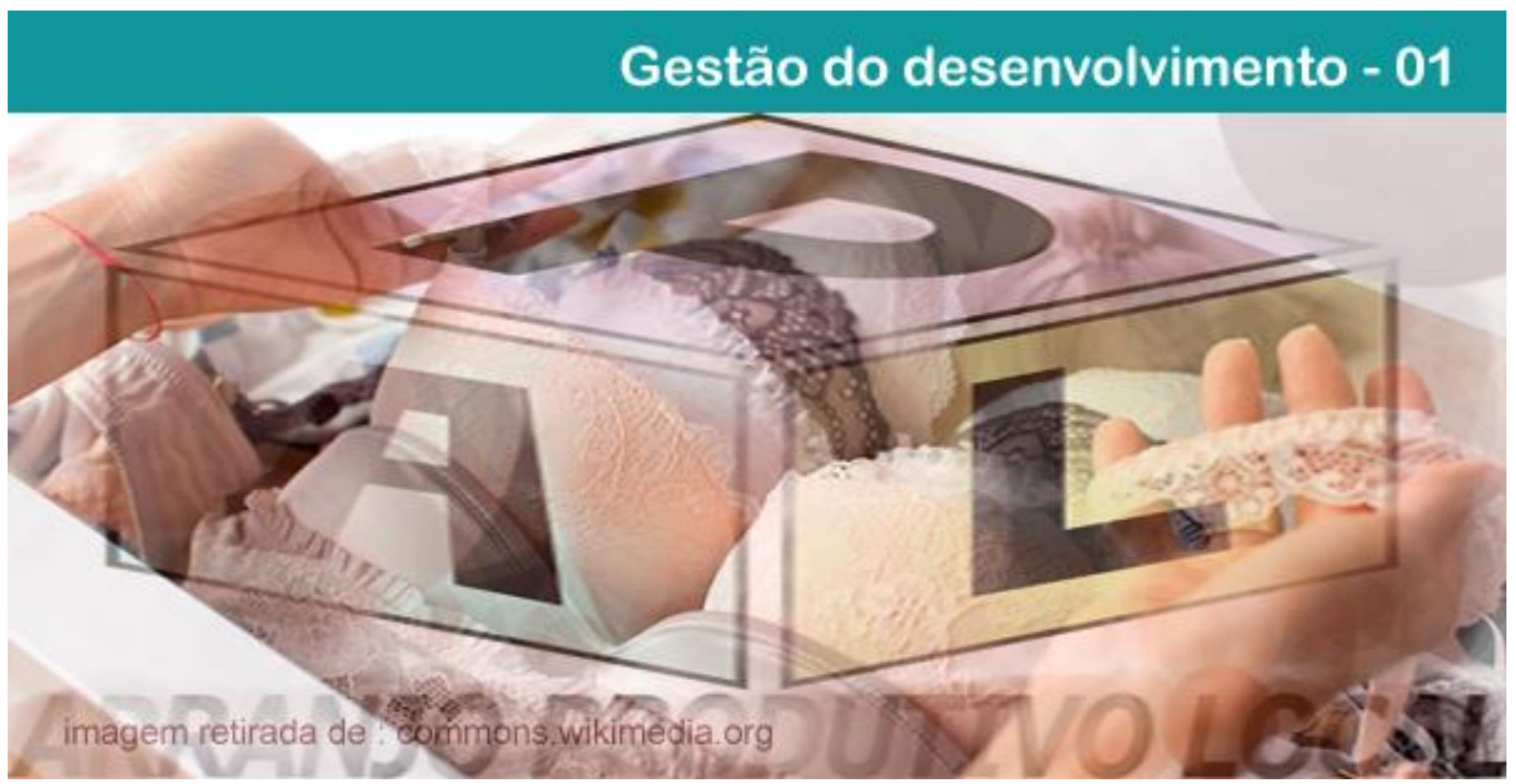

\title{
ANÁLISE DO PROGRAMA PROMOS/SEBRAE/BID NO ARRANJO PRODUTIVO DE MODA ÍNTIMA DE NOVA FRIBURGO SOB A ÓTICA SISTÊMICA
}

\section{Elaine Cavalcante Peixoto Borin}

Professora da Faculdade de Engenharia da UERJ e Pesquisadora da Rede de Pesquisa em Arranjos e Sistemas Produtivos e Inovativos Locais - RedeSist/UFRJ. E-mail: elaine.borin@ig.com.br.

\section{Israel Sanches Marcellino}

Doutorando em Economia pelo PPGE/IE/UFRJ e Pesquisador da RedeSist/UFRJ. E-mail: sanchesisrael@gmail.com.

Resumo: No final da década de 1990, o Arranjo Produtivo Local (APL) de moda íntima de Nova Friburgo foi identificado por atores de política do estado do Rio de Janeiro, e passou a ser alvo de iniciativas de promoção. Uma delas foi o Programa de Desenvolvimento de Distritos Industriais do Serviço Brasileiro de Apoio à Micro e Pequena Empresa (SEBRAE), do Instituto Promos (PROMOS) e do Banco Interamericano de Desenvolvimento (BID), que representou um ponto de inflexão na trajetória de políticas de desenvolvimento do arranjo, pois a partir desse programa um número considerável de outras instituições passou a desenvolver ações de apoio. Essa capacidade de inspirar outras experiências, através da visibilidade e do efeito-demonstração, torna a política em questão um objeto de análise relevante. $\mathrm{O}$ intuito deste trabalho é investigar se essa política teve um caráter sistêmico ou não. Acredita-se que esse tipo de análise contribui para a compreensão dos desafios mais amplos das políticas estaduais de APLs no Rio de Janeiro

Palavras-chaves: Arranjo produtivo local. Política sistêmica. Desenvolvimento local.

\section{ANALYSIS ON THE PROMOS/SEBRAE/BID PROGRAM IN THE NOVA FRIBURGO INTIMATE FASHION PRODUCTIVE SYSTEM UNDER A SYSTEMIC PERSPECTIVE}

Abstract: At the end of the 1990s, the Local Productive and Innovative System (LIPS) of intimate fashion in Nova Friburgo were identified by political actors from the state of Rio de Janeiro, and became the target of promotional initiatives. One of those was the Industrial Districts Development Program, promoted by SEBRAE, PROMOS and IDB, which represented a turning point in the development policies path of the system, since a considerable number of other institutions began to promote support actions. This ability to inspire other experiences through its visibility and demonstration-effect makes the policy in question a relevant object of analysis. The purpose of this paper is

\section{POLÊM!CA $\mid$ LABORE}

Polêmica - Revista Eletrônica da Uerj - Rua São Francisco Xavier, 524, $1^{\circ}$ andar bloco D, sl.1001 • Tels.: +55 21 2334-4088 / 4087 • http://www.e-publicacoes.uerj.br/index.php/polemica/index http://www.labore.uerj.br • laboreuerj@yahoo.com.br 
to investigate whether this policy were systemic or not. This type of analysis is helpful to the understanding about the broader challenges of the Rio de Janeiro LIPS policies.

Keywords: Local productive arrangement. Systemic policy. Local development.

\section{Introdução}

A história da indústria têxtil na região de Nova Friburgo remete ao início do século XX, quando do surgimento e crescimento de empresas de grande porte, principalmente, a Filó S/A, antiga subsidiária da transnacional Triumph. Dentre os produtos feitos na região, peças de moda íntima sempre tiveram uma posição de destaque neste período. Na década de 1980, no contexto de crise econômica de impactos particularmente negativos sobre a indústria brasileira, o downsizing e o fechamento de muitas dessas fábricas provocaram numerosas demissões. A partir do final da década de 1980 se dá um processo de reestruturação da indústria têxtil local. Essa nova estrutura surge com a apropriação do maquinário da antiga fábrica por atores locais e a reconfiguração da produção que passou a ser feita, majoritariamente, por um número significativo de empresas de porte reduzido e com alto grau de informalidade (CASTRO, 2011).

Essa trajetória histórica ilustra a noção de que arranjos produtivos locais (APLs) se constituem em torno de capacidades produtivas e inovativas específicas ao contexto do território em que se inserem. Questões pertinentes à moda remetem ao senso estético popular construído historicamente e, portanto, específico ao contexto cultural nacional e regional. Dentro dessa percepção, é importante ressaltar que o território também é responsável por aportar valores simbólicos e culturais relevantes para as atividades do arranjo.

No final da década de 1990, essa aglomeração de produtores de moda íntima e outros produtos afins, como moda praia e moda fitness foi identificada por atores de política do estado do Rio de Janeiro e passou a ser alvo de iniciativas promoção. Realizado entre 2002 e 2006, o Programa de Desenvolvimento de Distritos Industriais, promovido conjuntamente pelo $\mathrm{SEBRAE}^{1}$, pelo Instituto Promos ${ }^{2}$ e pelo $\mathrm{BID}^{3}$, representou um ponto de inflexão na trajetória de políticas de promoção ao APL de moda íntima de Nova Friburgo ao passo que envolveu uma instituição internacional de destaque e um volume de recursos sem precedentes em iniciativas de apoio ao desenvolvimento local, pelo menos, no Rio de Janeiro.

Com essa inflexão na trajetória, veio grande visibilidade para o caso friburguense. Um número considerável de outras instituições passou a desenvolver ações de apoio ao arranjo,

\footnotetext{
${ }^{1}$ Serviço Brasileiro de Apoio à Micro e Pequena Empresa.

${ }^{2}$ Agência de Cooperação Internacional da Câmara de Comércio de Milão, doravante PROMOS.

${ }^{3}$ Banco Interamericano de Desenvolvimento.
}

\section{POLÊM!CA $\mid$ LABORE}

Polêmica - Revista Eletrônica da Uerj - Rua São Francisco Xavier, 524, $1^{\circ}$ andar bloco D, sl.1001 • Tels.: +55 21 2334-4088 / 4087 • http://www.e-publicacoes.uerj.br/index.php/polemica/index http://www.labore.uerj.br • laboreuerj@yahoo.com.br 
conferindo a essas iniciativas um caráter emblemático para muitas delas. No caso do SEBRAERJ, por exemplo, a experiência de apoio ao APL gerou a formação de um quadro de referência metodológico para todas as políticas de estímulo ao desenvolvimento local do órgão no estado (EPSZTEJN; REGAZZI, 2001).

Essa capacidade de inspirar outras experiências através da sua visibilidade e do efeitodemonstração torna a política em questão um objeto de análise relevante. A época em que essa política foi executada se caracterizou pela ascensão da ideia de APL, dentro da agenda instituições voltadas a promover o desenvolvimento. Sendo que a política em questão é considerada um caso paradigmático de sucesso, é razoável dizer que, pelo menos no nível estadual, ela teve grande influência sobre as experiências posteriores.

Dado que a política fluminense de APLs apresenta desafios a serem superados (BRITTO et al, 2010), avançar na compreensão do quanto a política do SEBRAE/PROMOS/BID para o APL de Nova Friburgo é aderente à perspectiva de sistemas de inovação é relevante. Essa relevância vai no sentido de identificar até que ponto essa iniciativa aderiu, de fato, à perspectiva sistêmica embutida na abordagem de APLs. Acredita-se que esse tipo de análise contribui para a compreensão de desafios mais amplos das políticas estaduais de APL no Rio de Janeiro.

O intuito deste trabalho, portanto, é investigar se a política em foco teve um caráter sistêmico ou não. Para atingir esse objetivo, o trabalho se subdivide em quatro partes, além dessa introdução. A primeira seção se dedica a expor a visão dos autores da RedeSist ${ }^{4}$ sobre as experiências de política para APLs no Brasil, indicando as linhas gerais das recomendações normativas dessa literatura. A segunda seção consiste em uma descrição do Programa de Desenvolvimento de Arranjos Produtivos Locais, a política a ser analisada. A terceira seção consiste na análise crítica da política, pela ótica sistêmica. Essa análise, além de incluir uma parte de fundo teórico, também apresenta dados secundários que ilustram a trajetória do APL. A quarta e última seção, por fim, apresenta as considerações finais.

\footnotetext{
${ }^{4}$ Rede de Pesquisa em Arranjos e Sistemas Produtivos e Inovativos Locais. Uma rede de pesquisa interdisciplinar, formalizada desde 1997, sediada no Instituto de Economia da Universidade Federal do Rio de Janeiro e que conta com a participação de várias universidades e institutos de pesquisa no Brasil, além de manter parcerias com outras instituições da América Latina, África, Europa e Ásia. Foi no escopo das reflexões deste grupo que se desenvolveu a abordagem de APLs (CASSIOLATO; LASTRES, 1999).
}

\section{POLÊM!CA $\mid$ LABORE}

Polêmica - Revista Eletrônica da Uerj - Rua São Francisco Xavier, 524, $1^{\circ}$ andar bloco D, sl.1001 • Tels.: +55 21 2334-4088 / 4087 • http://www.e-publicacoes.uerj.br/index.php/polemica/index http://www.labore.uerj.br • laboreuerj@yahoo.com.br 


\section{As políticas para APLs e seu caráter sistêmico}

A abordagem de APLs é um marco teórico-conceitual alinhado com o entendimento de que sistemas de inovação têm sua dinâmica e configuração fortemente condicionadas por determinantes locais próprios ao território ${ }^{5}$. Vale destacar que a compreensão de território considerada por essa abordagem se relaciona com a visão da Nova Geografia ${ }^{6}$, compreendendoo a partir de quatro dimensões: econômica, cognitiva, sociopolítica e simbólica. Essas quatro frentes captam a essência das especificidades estruturais do sistema refletidas nas relações sociais, econômicas e políticas subjacentes ao território. Além das relações entre indivíduos, essa perspectiva também permite que sejam abarcados outros aspectos pertinentes aos laços constituídos pelas ideias e visões de mundo compartilhadas, essenciais para a formação de uma base de conhecimentos tácitos e de processos de aprendizado e inovação.

Nesse sentido, um APL é formado por uma ampla gama de agentes como empresas, usuários, fornecedores, prestadores de serviços, instituições científico-tecnológicas, universidades e órgãos de políticas, cujas interações ditam sua dinâmica. Essa dinâmica é amplamente determinada pela capacidade dos elementos do arranjo de criar, absorver e articular conhecimentos localmente de forma a gerar inovações. Quanto mais um arranjo é dotado dessa capacidade, mais intensa sua dinâmica e, portanto, melhores suas condições de competir e gerar desenvolvimento local.

Constituído por seus elementos internos e pelas interações entre eles, é importante mencionar que um APL não se encerra exclusivamente na esfera local, constituindo um sistema aberto. Estabelece relações com elementos pertinentes às escalas regional, nacional e internacional. A inserção do arranjo no contexto internacional é determinada por sua dinâmica, pelas características do seu tecido produtivo e pelo contexto econômico internacional e da condição do país na configuração da geopolítica internacional. Nas escalas nacional e regional, além dos vínculos estabelecidos pelo sistema produtivo e com a demanda, a inserção do APLé determinada pela sua interface com as políticas explícitas e implícitas dos sistemas nacional e regional de inovação.

A Figura 1 mostra um esquema de representação de um APL com as especificidades locais, regionais, nacionais e internacionais.

\footnotetext{
5 Salienta-se que os termos APL e Sistema Local de Inovação podem ser considerados como sinônimos (CASSIOLATO; LASTRES, 1999).

${ }^{6} \mathrm{Na}$ linha proposta por Raffestin (1993) e Santos (2000).
}

\section{POLÊM!CA $\mid$ LABORE}

Polêmica - Revista Eletrônica da Uerj - Rua São Francisco Xavier, 524, $1^{\circ}$ andar 
Figura - 1: Esquema de um APL e o Subsistema de Produção e Inovação

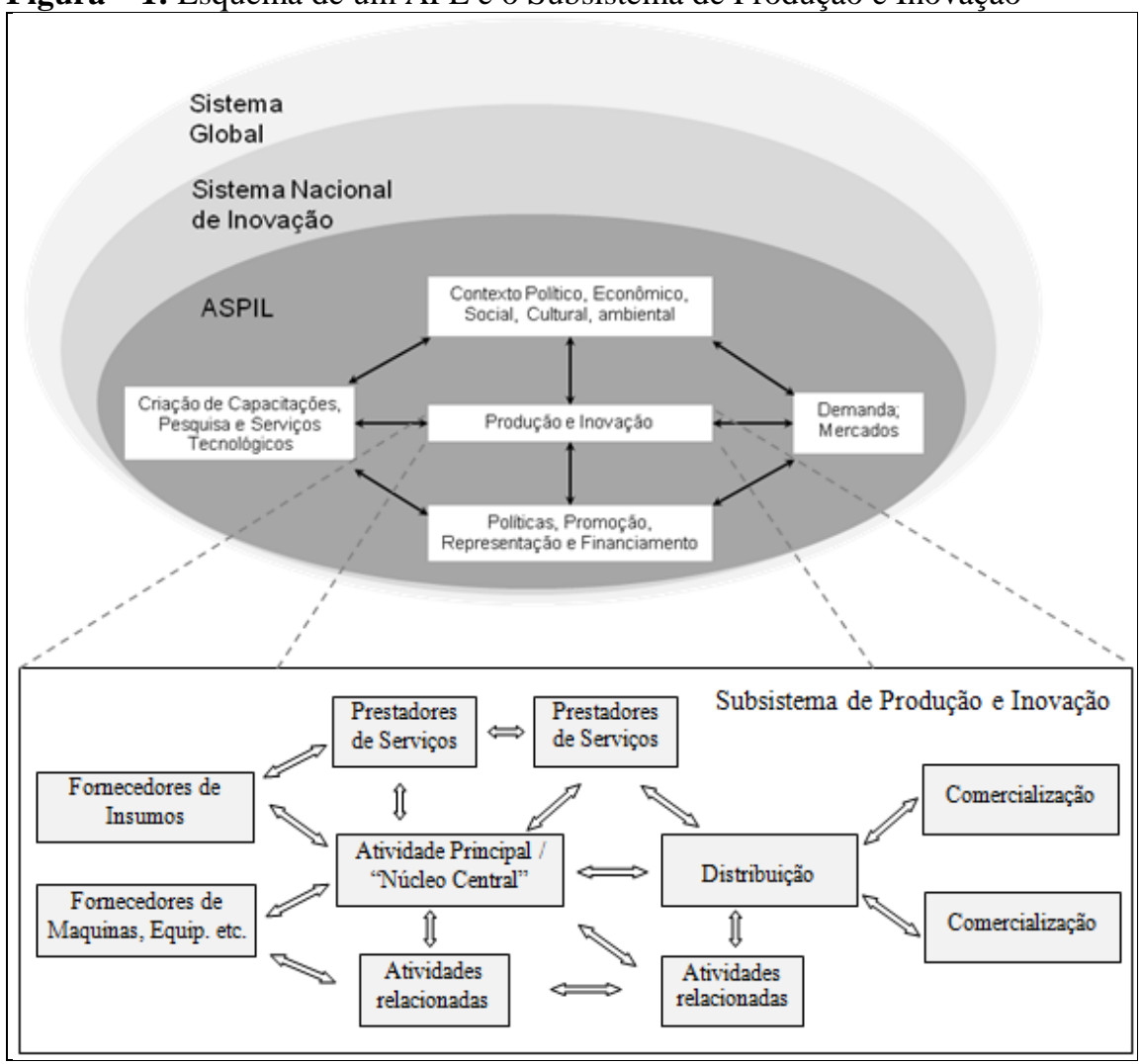

Fonte: MATOS et al, 2017.

Conforme Cassiolato e Lastres (2005), o conceito de APLs comporta qualidades em comparação a outros tradicionalmente utilizados por órgãos de políticas para tratar de temáticas relacionadas ao desenvolvimento local.

Segundo Garcez et al (2010), desde que foi desenvolvido, no final da década de 1990, o conceito de APLs se difundiu rapidamente. Essa difusão foi acompanhada do desenvolvimento de toda uma institucionalidade formal em diferentes órgãos de política irradiada, principalmente, mas não exclusivamente, a partir do o GTP-APL/MDIC ${ }^{7}$. Os avanços do processo derivado da adoção desse conceito podem ser sintetizados em três: (i) representou um resgate, naquele contexto, das políticas de desenvolvimento com a preocupação nas especificidades territoriais; (ii) a inclusão de atividades, atores e regiões normalmente pouco contemplados pelas ações de apoio e (iii) a intensificação das articulações e esforços de coordenações de ações de política em diferentes escalas.

\footnotetext{
${ }^{7}$ Grupo de Trabalho Permanente em APLs do Ministério de Desenvolvimento Indústria e Comércio Exterior (MDIC). Criado em 2004, este órgão está ligado à Coordenação-Geral de Arranjos Produtivos Locais, da Secretaria do Desenvolvimento e Competitividade Industrial do MDIC e é o órgão responsável por coordenar a política federal para APLs.
}

\section{POLÊM!CA $\mid$ LABORÉ}

Polêmica - Revista Eletrônica da Uerj - Rua São Francisco Xavier, 524, $1^{\circ}$ andar bloco D, sl.1001 • Tels.: +55 21 2334-4088 / 4087 • http://www.e-publicacoes.uerj.br/index.php/polemica/index http://www.labore.uerj.br • laboreuerj@yahoo.com.br 
Contudo, a celeridade desse processo de difusão também veio acompanhada de limitações, registradas pelo estudo "Mapeamento e análise das políticas para Arranjos Produtivos Locais no Brasil", coordenado pela RedeSist, entre 2008 e 2009 (APOLINÁRIO; SILVA, 2010; CAMPOS et al., 2010). De acordo com os resultados sistematizados nesse projeto de pesquisa, que investigou políticas para APLs nos 26 estados brasileiros, essas limitações resultam de: incompreensões sobre o referencial de APLs; permanências de rotinas, instrumentos e percepções associadas às políticas tradicionais (não sistêmicas e baseadas em modelos genéricos) e; de deficiências nos arcabouços institucionais que limitam a capacidade de coordenação de ações entre os vários órgãos de política que atuam sobre um mesmo APL.

Sobre o primeiro ponto, destaca-se a incorporação do termo ao discurso das políticas institucionais sem correspondência em termos de mudanças de concepção. Em outras palavras, a velocidade da difusão do termo e dos conceitos da abordagem, muitas vezes, foi acompanhada pela permanência de práticas tradicionalmente adotadas por instituições. Como resultado, essa 'apropriação' do framework por policymakers foi um processo permeado de distorções. Mais objetivamente, muitos órgãos de política acabaram por adotar concepções excessivamente restritivas de APLs tendendo a defini-los apenas como aglomerações produtivas ou estruturas de governança.

Como desdobramento desse primeiro ponto, as mudanças em termos de instrumentos e foco das políticas esperadas, levando-se em consideração as implicações da perspectiva neoschumpeteriana para políticas de inovação, tampouco encontraram seu correspondente. De fato, reconhecidos os já citados avanços que a adoção, mesmo que parcial, da visão de APLs trouxe às políticas de desenvolvimento no Brasil, o modus operandi dessas políticas ainda guarda limitações importantes. A essência dessas limitações deriva da permanência de práticas e instrumentos próprios do paradigma de políticas horizontais e verticais e de visões e metodologias próprios de políticas influenciadas pela perspectiva do neoliberalismo. Logo, é comum a prática de políticas não sistêmicas e não estruturais.

Segundo Gadelha (2001), as políticas não sistêmicas são aquelas que ignoram seus impactos sobre a coletividade dos atores presentes no território focalizando empresas, ou grupos específicos, a despeito do potencial de desestruturar articulações entre esses beneficiados e aqueles não beneficiados pela política presentes no território. Já as políticas não estruturais são aquelas inspiradas em modelos frequentemente inspirados em benchmarks, mimetizados de forma acrítica e em total desconexão com as especificidades do contexto do território. Esse tipo

\section{POLÊM!CA | LABORÉ}

Polêmica - Revista Eletrônica da Uerj - Rua São Francisco Xavier, 524, $1^{\circ}$ andar

bloco D, sl.1001 • Tels.: +55 21 2334-4088 / 4087 • http://www.e-publicacoes.uerj.br/index.php/polemica/index http://www.labore.uerj.br • laboreuerj@yahoo.com.br 
de política tende e ter resultados praticamente nulos ou mesmo prejudiciais ao ignorar fatores que podem ser cruciais para a realidade na qual se atua e que não o eram nos contextos dentro dos quais os modelos se sustentaram como casos de sucesso.

Com relação ao desenho do arcabouço institucional, as limitações que se desdobram são típicas de falhas de coordenação e ausência de convergência com uma estratégia nacional, ou pelo menos regional/estadual, de desenvolvimento. De fato, é muito comum que diferentes instituições levem a cabo simultaneamente, ou em períodos muito próximos no tempo, ações de apoio a um mesmo APL. Tendo essas ações o mesmo objeto, a articulação interinstitucional encerra um grande potencial de sinergias na direção de uma atuação coordenada e de maior fôlego para direcionar variados recursos de forma mais bem estruturada e escopo refinado. Contudo, na ausência dessa convergência de reconhecimento sobre papéis institucionais, objetivos e focos de atuação, é comum que ocorra o contrário com superposições, contradições e outras fontes de ineficácia típicas da descoordenação de ações autocentradas.

A riqueza das evidências empíricas organizadas pela trajetória de pesquisa da RedeSist sobre o tema proporcionou a formulação de um conjunto de propostas para novas políticas para APL (CASSIOLATO; LASTRES, 2005; APOLINARIO; SILVA, 2010; CAMPOS et al, 2010; CASSIOLATO; MATOS, 2012). É crucial notar que essas propostas nada têm que possam soar como 'modelo ideal' de políticas para APL, uma vez que, por suposto, tal coisa inexiste. Antes de tudo, trata-se de um conjunto articulado de proposições, fundamentadas na análise contextualizada dos avanços e limitações das políticas de APL do Brasil, na década passada, e realizado com o fito de contribuir para o seu aperfeiçoamento.

Conforme sintetizam bem Garcez et al (2010), esse conjunto de proposições gira em torno de três pontos. O primeiro é trazer para o foco central das ações a assimilação e a incorporação de conhecimento e a inovação, reconhecendo-os como base para a construção de capacitações produtivas e inovativas e para o desenvolvimento de longo prazo. O segundo é incluir definitivamente a variável territorial às políticas, levando as especificidades do contexto como pressuposto para o planejamento, o desenho e a execução das iniciativas de apoio. Por último, cabe estimular ações coletivas e sistêmicas, superando práticas tradicionais, buscando o desenvolvimento de novas formas de apoio que enfatizem o papel das sinergias e interações entre os atores dentro de um APL e entre APLs.

Como complemento a ser levado em consideração, é possível apontar um quarto ponto levantado por Cassiolato e Matos (2012), segundo os quais as novas políticas de APL devem

\section{POLÊM!CA $\mid$ LABORE}

Polêmica - Revista Eletrônica da Uerj - Rua São Francisco Xavier, 524, $1^{\circ}$ andar

bloco D, sl.1001 • Tels.: +55 21 2334-4088 / 4087 • http://www.e-publicacoes.uerj.br/index.php/polemica/index http://www.labore.uerj.br • laboreuerj@yahoo.com.br 
ser guiadas por um enfoque mais amplo, baseado em uma estratégia de desenvolvimento produtivo e inovativo para o Brasil. Nesse sentido, destaca-se a importância da superação de visões equivocadas a respeito do desenvolvimento de longo prazo como supostas contradições intrínsecas entre os objetivos do desenvolvimento econômico, o desenvolvimento social e o eco desenvolvimento ou entre os imperativos do desenvolvimento local, principalmente, o de regiões marginalizadas, e o desenvolvimento nacional. Dispensando-se a visão economicista subjacente a essas supostas contradições, os autores argumentam que o eixo norteador das políticas de APL deve ser uma estratégia de desenvolvimento de longo prazo ampla e integrada em substituição ao espaço excessivo ocupado por discussões metodológicas como, por exemplo, os critérios para a validação da existência ou não de um APL.

\section{O Programa Promos/Sebrae/BID}

O APL de Confecções e Moda Íntima de Nova Friburgo e Região teve um importante marco de políticas, no final da década de 1990, e outro no início da década de 2000. Entre 1997 e 1998, um estudo técnico realizado pela FGV (1998) com apoio de SEBRAE, FIRJAN ${ }^{8}$ e do Governo do Estadual identificou e deu visibilidade ao arranjo com divulgação de grande repercussão entre os órgãos de política. Nesse mesmo ano, algumas instituições iniciaram suas primeiras iniciativas de apoio.

No início dos anos 2000, estimuladas pela visibilidade do arranjo, outras instituições também iniciaram ações de apoio, como a Caixa Econômica Federal, o Banco do Brasil e o $\mathrm{BNDES}^{9}$, na área de crédito, a $\mathrm{APEX}^{10}$, na área de comércio exterior, o Governo Estadual com concessão de incentivos fiscais e iniciativas na área de Ciência e Tecnologia (C\&T) via UERJ ${ }^{11}$, SECTI $^{12}$, entre outras (LA ROVERE et al, 2000; LEMOS et al, 2004). O segundo marco histórico de políticas do APL, no período, acontece em 2002, com o início do programa realizado por SEBRAE, PROMOS e $\mathrm{BID}^{13}$, que se estendeu até 2006. Essa iniciativa foi emblemática por se tratar de uma iniciativa de envergadura orçamentária sem precedentes para a região, na ordem de 5 milhões de dólares em valores da época (REGAZZI, 2007).

\footnotetext{
${ }^{8}$ Federação das Indústrias do Estado do Rio de Janeiro.

${ }^{9}$ Banco Nacional do Desenvolvimento Econômico e Social.

${ }^{10}$ Agência Brasileira de Promoção de Exportações e Investimentos.

${ }^{11}$ Universidade do Estado do Rio de Janeiro.

${ }^{12}$ Secretaria de Ciência, Tecnologia e Inovação do Estado do Rio de Janeiro.

${ }^{13}$ Doravante, Programa SEBRAE/PROMOS/BID.
}

\section{POLÊM!CA $\mid$ LABORE}

Polêmica - Revista Eletrônica da Uerj - Rua São Francisco Xavier, 524, $1^{\circ}$ andar bloco D, sl.1001 • Tels.: +55 21 2334-4088 / 4087 • http://www.e-publicacoes.uerj.br/index.php/polemica/index http://www.labore.uerj.br • laboreuerj@yahoo.com.br 
Segundo Borin (2006), a configuração institucional do programa envolveu o SEBRAE como principal instituição em termos de dotação de recursos, operação das políticas no território e responsável pela consolidação do desenho metodológico. O Instituto PROMOS, agência de promoção de parcerias internacionais da Câmara de Comércio de Milão, teve uma atuação mais discreta no caso fluminense, inserindo-se com mais ênfase junto ao SEBRAE nacional e com papel decisivo de influência no processo de construção do arcabouço teórico-conceitual da política (i.e. SEBRAE, 2002). O BID, enquanto instituição de fomento, transferiu recursos através do FUMIN ${ }^{14}$ e teve papel importante no monitoramento, fiscalização e avaliação da política que derivou de programa submetido pelo SEBRAE e pelo Instituto PROMOS, através de uma chamada lançada pela instituição. Esse papel, contudo, foi além dessas funções ao passo que o BID também foi importante em influenciar decisões relacionadas ao desenho da política e à seleção dos APLs apoiados ${ }^{15}$.

O programa propôs quatro componentes fundamentais que nortearam tanto o modus operandi da sua execução quanto a lógica de construção de indicadores para monitoramento de processos e avaliação de resultados (ibid, 2002). O primeiro deles chamava-se fortalecimento da dinâmica de distrito industrial, cujas medidas concretas recomendadas foram no sentido de construir a governança, estimular parcerias entre empresários, criar um centro de serviços e criar uma marca ou selo de indicação geográfica. O segundo, informação e acesso ao mercado, teve o objetivo de estimular a formulação de estratégias empresariais; a logística e distribuição na compra de insumos e venda de produtos e a incorporação do design no repertório de vetores estratégicos para as empresas. O terceiro foi organização da produção, relacionado ao aumento da produtividade e à redução de custos. As iniciativas foram voltadas à formação em gestão empresarial; à capacitação técnica dos trabalhadores e; ao apoio à difusão de novas tecnologias. O último componente foi internacionalização das micro e pequenas empresas, cujas medidas principais foram o apoio à realização de missões empresariais internacionais; a participação em feiras e eventos no Brasil e no exterior; a promoção de consórcios de exportação e o suporte às atividades de marketing e publicidade.

Segundo análises dos órgãos responsáveis pelo Programa, o APL pode ser considerado um caso bem-sucedido no que se refere às políticas de apoio. A base para tais afirmações são os indicadores de avaliação propostos pelos órgãos executores (SEBRAE, 2002), que

\footnotetext{
${ }^{14}$ Fundo Multilateral de Investimentos do BID.

${ }^{15}$ Além do APL de Nova Friburgo, foram apoiados outros três APLs: o de Móveis de Paragominas (PA), o de Confecções de Tobias Barreto (SE) e o de Calçados de Campina Grande (PB).
}

\section{POLÊM!CA $\mid$ LABORE}

Polêmica - Revista Eletrônica da Uerj - Rua São Francisco Xavier, 524, $1^{\circ}$ andar 
constituíam metas a serem atendidas no escopo dos quatro componentes. Segundo SEBRAE (2006), o programa atendeu a 90\% das metas, faltando avanços na estruturação de um centro de serviços e na área de exportações.

O principal resultado finalístico da política, para Borin (2006), foi o aumento do volume total de vendas (faturamento) e das empresas do arranjo. Os resultados intermediários, que na concepção dos policymakers, levaram a esse desempenho, envolveram o aumento do investimento das empresas em marketing, o aumento da produtividade - em termos de volume total de vendas por unidade de trabalho empregada (REGAZZI, 2007) -; a criação de selos de origem e de qualidade; aumento das práticas de renovação de modelos das empresas e a elevação da quantidade de empresas exportando.

Uma informação complementar importante é o fato de o programa ter pretendido um modelo geral passível de replicação, pelo menos, para diferentes APLs no Brasil e em outros países da América Latina. De fato, conforme relatório de avaliação da política divulgado pelo BID (FUMIN, 2010), instituições de Argentina, Chile, Colômbia, Equador, México e Peru explicitaram seu interesse em adotar a metodologia de desenvolvimento de arranjos produtivos locais. Remetendo-se a essa natureza de pretensa fórmula ideal subjacente ao discurso da política é que se realizará sua análise na próxima seção.

\section{Análise da política sob a perspectiva sistêmica}

\section{A concepção teórica e conceitual do Programa}

Avaliando a programa SEBRAE/PROMOS/BID desde a perspectiva sistêmica, um primeiro ponto crítico está na postura metodológica assumida diante da base teórico-conceitual. Segundo SEBRAE (2002), ponto de partida da política é a ideia de que os distritos industriais italianos (DIs) ${ }^{16}$ constituem um modelo ideal a ser perseguido pelo conjunto de empresas e instituições de todos os APLs apoiados, inclusive o de Nova Friburgo. Toma-se, explicitamente, o modelo dos DIs como um paradigma capaz de ser transplantado para todo e qualquer território

\footnotetext{
${ }^{16}$ Esse conceito foi aportado como base para a implementação da política, provavelmente, por influência do Instituto Promos (BORIN, 2006). Trata-se de um arcabouço desenvolvido por autores como Bagnasco (1977), Brusco (1986) e Becattini (1978; 1987), interessados em compreender como as aglomerações produtivas de micro e pequenas empresas da terceira Itália foram importantes para o desenvolvimento econômico daquele país desde o pós-guerra. A literatura em torno dos DIs é reconhecida por mesclar elementos de análise econômica com a geografia e outras ciências sociais, criando um quadro de referência teórico-conceitual contextualizado e especificamente voltado para a compreensão do caso italiano e suas especificidades. A difusão desse arcabouço conceitual, contudo, levou à sua descontextualização e replicação acrítica para outras realidades.
}

\section{POLÊM!CA $\mid$ LABORE}

Polêmica - Revista Eletrônica da Uerj - Rua São Francisco Xavier, 524, $1^{\circ}$ andar bloco D, sl.1001 • Tels.: +55 21 2334-4088 / 4087 • http://www.e-publicacoes.uerj.br/index.php/polemica/index http://www.labore.uerj.br • laboreuerj@yahoo.com.br 
a qualquer momento histórico, apenas a partir do seguimento de "melhores práticas". Esse benchmark nada mais é do que um conjunto de prescrições de políticas formulado a partir de um exercício de generalização da literatura de DIs, abstraindo-se o contexto no qual essas experiências ocorreram e foram analisadas.

Outro ponto problemático, associado ao primeiro, é a forma como o conceito de APL a princípio, sistêmico - se encaixa nessa base teórico-conceitual. O discurso do programa incorpora o termo APL de maneira, no mínimo, eclética, considerando o desenvolvimento de um distrito industrial como um evento subdividido em etapas evolutivas sequenciais (Aglomeração produtiva - APL - Sistema Local de Inovação - Distrito Industrial). Essa assimilação do termo se dá com severos prejuízos à essência do conceito. O prejuízo mais latente é o fato de se desconsiderar toda a estrutura de pensamento subjacente aos microfundamentos neoschumpeterianos que baseiam a abordagem de sistemas de inovação ${ }^{17}$.

Essa base de microfundamentos, implicitamente, é substituída pela visão microeconômica marshalliana ${ }^{18}$ característica da abordagem de DIs. Essa diferença é crucial para que ideias importantes ao programa, como competitividade e eficiência, sejam interpretadas de acordo com a estrutura de pensamento neoclássica. Nesse sentido, a competitividade e a eficiência de um APL ou DI seriam determinadas pela capacidade das empresas em interagir em um contexto de proximidade geográfica para gozar dos benefícios das externalidades de aglomeração e de outros fatores socioeconômicos. O tipo de vantagem competitiva a ser construída dentro desse DI, necessariamente, se sustentaria nessas externalidades pecuniárias e tecnológicas, traduzindo-se em uma maior eficiência produtiva.

Os mesmos termos integram a linguagem conceitual neoschumepeteriana, mas com diferenças conceituais significativas. A noção de competitividade, por exemplo, é essencialmente diferente se observada do ponto de vista da empresa e do ponto de vista do APL. Essa competitividade sistêmica (FAJNZYLBER, 1988) se ancora na capacidade desse sistema

\footnotetext{
${ }^{17}$ Esses microfundamentos são: (i) a ideia da firma enquanto um conjunto de recursos, (ii) a competição como processo dinâmico de busca por vantagens competitivas; (iii) a inovação como base para a construção de vantagens competitivas sobre concorrentes; (iv) o mercado como ambiente econômico no qual os processos de busca por novas tecnologias são selecionados como mais competitivos e, portanto, bem sucedidos na concorrência; e (v) o caráter limitado da racionalidade como fator gerador de incertezas fundamentais, da impossibilidade de nortear as escolhas por cálculos maximizadores e a irrelevância do conceito de equilíbrio de mercado.

${ }^{18}$ Visão ortodoxa, ou neoclássica, do pensamento econômico, que entende as empresas como: (i) unidades maximizadoras de lucros, (ii) capazes de tomar decisões alocativas sem enfrentar incertezas incontornáveis por cálculos de risco ou limitações cognitivas (iii) em um mercado que converge ao equilíbrio (iv) determinado por uma concorrência estática, determinado pela capacidade das empresas em tomar decisões antecipando as ações dos seus concorrentes.
}

\section{POLÊM!CA $\mid$ LABORE}

Polêmica - Revista Eletrônica da Uerj - Rua São Francisco Xavier, 524, $1^{\circ}$ andar bloco D, sl.1001 • Tels.: +55 21 2334-4088 / 4087 • http://www.e-publicacoes.uerj.br/index.php/polemica/index http://www.labore.uerj.br • laboreuerj@yahoo.com.br 
de inovação em proporcionar às firmas condições que as permitam manter processos de aprendizado perenes e estratégias de inovação mais ativas, e não apenas passivas. A eficiência daí se deriva pela capacidade deste arranjo em se adaptar às mudanças no ambiente econômico, isto é, à resiliência do APL. E as vantagens competitivas dinâmicas construídas neste cenário derivariam de inovações que permitem as empresas do arranjo a se diferenciar de concorrentes de dentro e de fora do arranjo, criando novos espaços econômicos para a acumulação e o crescimento.

Vale destacar que a noção de competitividade colocada no sentido da perspectiva de DIs, por se basear em competição via preços e redução de custos, é tida na literatura neoschumpeteriana como competitividade espúria, em contraste com a competitividade sistêmica (FAJNZYLBER, 1988). Essas vantagens competitivas, originadas apenas pelos custos e concorrência via preços e não através da qualidade de produtos, são consideradas pela abordagem neoschumpeteriana como fontes de competitividade espúria.

\section{$\underline{O}$ desenho e a metodologia de implementação}

Com relação ao desenho da política em si, o principal problema se desdobra do foco em DIs, cujo cerne é setorial. Ao privilegiar aquilo que dentro da perspectiva de APL se chama de subsistema de produção, mais especificamente a atividade principal desse subsistema (confecções), a política deixou em segundo plano duas dimensões importantes.

A primeira dessas dimensões é a cadeia produtiva em senso mais amplo. $\mathrm{O}$ arranjo de moda íntima inclui em seu subsistema de produção, além das atividades de confecção de lingerie, outros tipos de confecções nas áreas de moda praia e moda fitness, além de todo um conjunto de atividades relacionadas aos fornecedores e ao comércio. Abordar a intervenção no arranjo pela ótica de DIs negligencia em seu planejamento os impactos colaterais sobre essas outras atividades que integram o arranjo. No limite, os estímulos podem ser caracterizados como não sistêmicos, uma vez que não têm como público alvo a coletividade dos agentes do arranjo, mas sim apenas uma fração desta, mesmo que a mais significativa.

A segunda dimensão colocada em segundo plano é o território. Por privilegiar a perspectiva setorial, a política não levou em consideração a forma heterogênea como as atividades de um mesmo arranjo - e de todos os seus subsistemas - se organizam e se distribuem no território. Dentro da lógica produtiva, evidentemente, a parcela do público-alvo localizada em Nova Friburgo desfrutou de melhores condições para captar os frutos das ações de

\section{POLÊM!CA $\mid$ LABORÉ}

Polêmica - Revista Eletrônica da Uerj - Rua São Francisco Xavier, 524, $1^{\circ}$ andar

bloco D, sl.1001 • Tels.: +55 21 2334-4088 / 4087 • http://www.e-publicacoes.uerj.br/index.php/polemica/index http://www.labore.uerj.br • laboreuerj@yahoo.com.br 
promoção. Na lógica do subsistema de capacitações e pesquisa, Nova Friburgo também se viu privilegiada, ao passo que a maior parte das instituições voltadas à pesquisa e ao treinamento (com destaque à UERJ e ao SENAI) estão localizadas nesta cidade. Na lógica do subsistema de políticas, os benefícios também se concentraram na cidade-núcleo do APL, uma vez que é neste local que se concentram as principais instituições de promoção, representação e financiamento, como o SEBRAE, a FIRJAN e o Banco do Brasil.

Com relação aos componentes norteadores da execução, também há pontos que não convergem com a perspectiva sistêmica. Tratam-se de falhas derivadas dos erros de concepção no embasamento e no desenho da política. A execução da política foi guiada por uma preconcepção a respeito dos desafios ao desenvolvimento a ser enfrentados pelo APL. Ao ter como meta maior a adequação do arranjo ao paradigma de DIs, o roteiro de ações a serem desempenhadas e a percepção sobre os problemas a serem contornados não foram construídos a partir de um diagnóstico da realidade específica do objeto da política. Os problemas identificados giram em torno de duas questões: a desconsideração de especificidades estruturais relevantes do APL e o estímulo de adoção de 'melhores práticas'.

O componente fortalecimento da dinâmica de distritos industriais, que mirou a construção de capital social no APL, partiu de premissas equivocadas sobre a cultura no território. A perspectiva top down aí embutida gerou a visão de que uma cultura de associação e comportamento cooperativo entre os agentes poderia ser construída a partir de um sistema de incentivos criado pela política. Assim sendo, sob a perspectiva de ganhos mútuos, os agentes se associariam e gerariam - por meio de uma espécie de automatismo - mais ganhos mútuos derivados à própria associação em si. Se mantido por tempo suficiente, esse sistema de incentivos consolidaria a fonte desses ganhos derivados da nova cultura, podendo ser retirado sem prejuízos aos agentes. Estão, nesse contexto, duas simplificações grandes. Uma está em negligenciar o fato de que comportamentos associativos não necessariamente geram benefícios mútuos no curto prazo. Conjunturas negativas podem impactar todos os agentes, comprometendo essa possibilidade. A segunda está em compreender a cultura como uma coleção de hábitos rotineiros mantidos de forma autointeressada e que, portanto, pode ser construído por intervenções de órgãos de política.

O componente de informação e acesso ao mercado, provavelmente, é aquele que mais se aproximou da lógica sistêmica, ao permitir a criação de institucionalidade e mecanismos que geraram impactos mais amplos no arranjo. Ao estruturar esforços na área de marketing, por

\section{POLÊM!CA $\mid$ LABORÉ}

Polêmica - Revista Eletrônica da Uerj - Rua São Francisco Xavier, 524, $1^{\circ}$ andar

bloco D, sl.1001 • Tels.: +55 21 2334-4088 / 4087 • http://www.e-publicacoes.uerj.br/index.php/polemica/index http://www.labore.uerj.br • laboreuerj@yahoo.com.br 
exemplo, foram gerados insumos para o aprimoramento da Feira do Vestuário de Nova Friburgo, de forma a gerar visibilidade comercial às empresas do território. Ao promover atividades junto ao SENAI local, o programa também abriu caminho para o que mais tarde se tornou uma estrutura de capacitação bem articulada com órgãos de representação empresarial e voltada, especificamente, às necessidades de mão de obra das empresas locais. Como ponto negativo, por outro lado, pode-se apontar o foco em magazines como eixo de comercialização prioritário a ser estimulado. Essa ênfase, apesar de haver beneficiado empresas, não foi capaz de apoiar na mesma medida outras estratégias empresariais potencialmente virtuosas, como o desenvolvimento de marcas próprias e o fortalecimento de design e marcas locais.

No componente de organização da produção também há divergências significativas com a perspectiva sistêmica. $\mathrm{O}$ foco das ações contidas nesse campo de atuação foi a introdução de 'melhores práticas' pra tecnologias, produtos e processos. Essas 'melhores práticas', assumidas de maneira apriorística pela política e os esforços para sua adoção pelas empresas do arranjo, negligenciaram a existência de conhecimentos tácitos e de práticas correntes existentes no território e seu potencial enquanto possíveis fontes de resiliência e competitividade do arranjo. Não se trata de assumir, por um raciocínio inverso e tão falho quanto o empregado pela política, que necessariamente as práticas levadas a cabo no território são melhores que as práticas que se pretendeu introduzir. Trata-se de entender que a assunção da impossibilidade dessas práticas correntes superam as práticas propostas e está na linha da visão microfundamentada em princípios marshallianos, que desconsideram as especificidades do território, ao se balizar em hipóteses de concorrência neoclássica e homogeneidade.

Por último, no componente de internacionalização das MPEs também há problemas derivados da perspectiva top down. Trata-se de uma visão transplantada para a realidade do APL de forma prévia à realização de um diagnóstico sobre suas condições estruturais específicas. No início dos anos 2000, a vulnerabilidade externa da economia brasileira e o passado de alta inflação tornaram frequente a inclusão de ações de apoio à exportação em diversas iniciativas de política industrial. Isso, junto com a ação contemporânea da APEX no território, influenciou o desenho da política do SEBRAE. Como consequência, pode-se dizer que a visão sobre a realidade macroeconômica do período impactou o objetivo da política de maneira mais significativa que a interpretação específica da realidade do território e das reais necessidades a serem colocadas pelos agentes.

\section{POLÊM!CA | LABORE}

Polêmica - Revista Eletrônica da Uerj - Rua São Francisco Xavier, 524, $1^{\circ}$ andar 
Em consonância com o espírito do neoliberalismo à época, o foco de estimular as exportações deveria ser onipresente, a despeito de toda e qualquer característica estrutural do território. Certamente, esse erro de concepção gerou falhas de execução que determinaram a ineficácia das ações em tornar o APL de Nova Friburgo um eixo relevante de exportações de artigos de moda íntima.

Por último, dois problemas na esfera de execução da política tiveram caráter não sistêmico. O primeiro foi a forma de provimento das ações segundo a lógica de balcão e o segundo foi o prazo excessivamente curto para a realização de metas relativamente ambiciosas da política.

Com relação ao método de atendimento direto ao público-alvo da política, o provimento de ações e benefícios previstos estava condicionado ao pleiteamento destes por parte de empresários locais junto ao SEBRAE local. O engajamento desses empresários deveria ser estimulado pela adesão voluntária, mediante a divulgação da política e a sensibilidade do público a respeito das vantagens que ela oferecia. O sentido dessa metodologia é atrair novos 'clientes' a partir da publicidade feita em torno dos benefícios potenciais e dos resultados da política. Essa lógica é não sistêmica por privilegiar o enfoque ao agente econômico (empresa ou empresário) ao invés da coletividade do sistema.

De fato, o resultado efetivo da política em termos de sua cobertura é questionável uma vez que, conforme relatório do BID/FUMIN (FUMIN, 2010), o número de empresas atendidas foi de em torno 400 e, de acordo com SEBRAE (2006), desses 400, apenas 230 participaram de forma sistemática e continuada. Para ter uma noção do quão baixo é esse nível de cobertura, pode-se considerar que, em 2006, os municípios que oficialmente integram o APL contavam com aproximadamente 1.500 empresas formais (segundo dados do Ministério do Trabalho e Emprego) e com um número estimado de 750 empresas informais ${ }^{19}$. Ou seja, cerca de 2.250 existentes no APL de moda íntima de Nova Friburgo, apenas 10\% delas foram sistematicamente atendidas pela política.

O último ponto no qual a política analisada divergiu da abordagem sistêmica foi na relação entre resultados almejados e o prazo de execução. A despeito do caráter não sistêmico do desenho, das metas traçadas e das ações implementadas, a política teve o fito de induzir mudanças estruturais no arranjo. Essas mudanças eram compatíveis com o objetivo de

\footnotetext{
${ }^{19}$ Segundo estimativas realizadas pela Prefeitura Municipal de Nova Friburgo, na primeira metade da década de 2000, cerca de um terço das empresas integrantes do APL eram informais (HASENCLEVER, 2005).
}

\section{POLÊM!CA $\mid$ LABORE}

Polêmica - Revista Eletrônica da Uerj - Rua São Francisco Xavier, 524, $1^{\circ}$ andar

bloco D, sl.1001 • Tels.: +55 21 2334-4088 / 4087 • http://www.e-publicacoes.uerj.br/index.php/polemica/index http://www.labore.uerj.br • laboreuerj@yahoo.com.br 
transformar a realidade do APL de modo a adequá-la à realidade proposta pelo paradigma dos DIs. Ocorre, no entanto, que esse objetivo perseguido de maneira "curtoprazista" não conseguiu ser atingido, pois foi proposto um prazo de apenas quatro anos para a execução do programa. O “curtoprazismo" diverge da perspectiva sistêmica, uma vez que esta pressupõe ações articuladas em vários níveis em favor do sistema como um todo enquanto objeto da ação com o objetivo de alcançar resultados de desenvolvimento de longo prazo.

\section{Considerações finais}

A principal conclusão que se pode tirar das análises realizadas neste trabalho é que a política do SEBRAE/PROMOS/BID no APL de moda íntima de Nova Friburgo não teve um caráter sistêmico. Os vários pontos que a caracterizam enquanto não sistêmica têm como causa primária problemas de concepção básicos que se desdobraram na negligência sobre o papel do território e suas especificidades na dinâmica de evolução de um APL, e na adoção de uma perspectiva setorial essencialmente estreita. Políticas desse tipo podem gerar efeitos colaterais não previstos (distorções).

Os problemas de concepção seguem em duas direções. Uma é a adoção de uma base conceitual microfundamentada em uma abordagem marshalliana, que traz toda uma série de noções sobre temas essenciais para determinar o caráter à política como: empresa, competitividade e eficiência. Concomitantemente, outro problema de concepção, é a conceituação equivocada do termo APL, que foi incorporado ao discurso da política enquanto algo distinto de um sistema local de inovação e em sendo uma etapa parcial da evolução de um aglomerado produtivo na direção de um DI.

Sobre a negligência quanto à variável do território, os pontos de divergência com a abordagem sistêmica de APLs seguiu em três direções. A primeira é a prescrição de uma fórmula ideal baseada em uma noção particular de DI. A segunda, implicada pela primeira, é a prescrição de 'melhores práticas' a gerar resultados ótimos para todo e qualquer APL em todo e qualquer território e momento histórico. Por último, a terceira forma de abstrair o território enquanto variável central para uma política sistêmica de APL foi a abordagem essencialmente top down proposta pela política. A distinção dessa abordagem é sutil, pois, apesar de prever a participação de atores do território em processos decisórios, essa participação, em todos os momentos que foi mencionada no discurso da política, sempre era condicionada à ação pretensamente racional realizada de acordo com as 'melhores práticas' aprendidas com aqueles

\section{POLÊM!CA $\mid$ LABORE}

Polêmica - Revista Eletrônica da Uerj - Rua São Francisco Xavier, 524, $1^{\circ}$ andar

bloco D, sl.1001 • Tels.: +55 21 2334-4088 / 4087 • http://www.e-publicacoes.uerj.br/index.php/polemica/index http://www.labore.uerj.br • laboreuerj@yahoo.com.br 
que intervinham no APL. A inclusão de princípios de planejamento participativo e de outros preceitos que privilegiam o espaço para abordagens bottom up era condicionada à sua concordância prévia com os imperativos 'técnicos' universais prescritos pelas 'melhores práticas'.

O enfoque setorial estrito adotado pela política também foi ponto de divergência com a perspectiva sistêmica. Ao dar ênfase excessiva ao núcleo crítico do subsistema de produção do APL, a política acabou por cobrir com mais eficácia a parte mais 'visível' (conforme os dados secundários) do APL, negligenciando as invisibilidades associadas à informalidade e à distância do centro dinâmico do território (cidade de Nova Friburgo). Em outras palavras, a política adotou como princípio atuar sobre a parte mais visível do arranjo, deixando em segundo plano os atores mais marginalizados. Esse padrão de intervenção tem o potencial de acentuar desigualdades, ao passo que privilegia a capacidade dos atores menos necessitados em capturar os benefícios da política, enquanto minimiza a capacidade dos menos favorecidos em capturálos.

Por último, sinaliza-se a influência da política como um tipo de Leito de Procusto. No caso dos dados de emprego, que colaboram para dimensionar a estrutura produtiva do arranjo, a evolução das estatísticas aponta para a ocorrência de uma reconfiguração da cadeia produtiva local no sentido de intensificar a especialização na produção de moda íntima. Distorção incentivada pela política que privilegiou essa parte - a mais visível do arranjo, fonte de provável perda de competitividade sistêmica do arranjo, em virtude da perda de fontes de heterogeneidade. No caso de dados de comércio exterior, o Leito de Procusto gerou objetivos míopes, incapazes de observar o padrão de inserção internacional do APL (muito mais políticoinstitucional que comercial-econômica), promovendo esforços intensivos no provimento de informações e de treinamentos para o trato com trâmites burocráticos para a exportação, ao invés de enfocar em estratégias de construção de competências e capacitações internas às firmas voltadas à alteração de sua inserção internacional. Realizada com a fé em automatismos derivados das sinergias com os objetivos ligados à competitividade e à eficiência na acepção marshalliana dos termos, as ações de promoção à exportação levadas ao APL não produziram resultados efetivos nem de curto nem de longo prazo.

\section{POLÊM!CA | LABORE}

Polêmica - Revista Eletrônica da Uerj - Rua São Francisco Xavier, 524, $1^{\circ}$ andar 
Referências

APOLINÁRIO, V.; SILVA, M. (orgs) Políticas para arranjos produtivos locais: análise em estados do Nordeste e da Amazônia Legal. Natal: EDUFRJ, 2010.

BAGNASCO, A. Tre Italie: La problematica territoriale dello sviluppo italiano. Bolonha: Ii Mulino, 1977.

BECATTINI, G. The development of light industry in Tuscany. Economic Notes, v. 3. n. 2, 1978.

Il distretto industriale Marshalliano: Cronaca di un ritrovamento. In: (ed.). Mercato e forze

locali: II distretto industriale. Bolonha: Ii Mulino, 1987.

BRUSCO, S. Small firms and industrial districts: The experience of Italy. In KEEBLE, D.; WEVER, E. (eds.). New finns and regional development. Londres: Croom Helm, 1986.

BORIN, E. O SEBRAE e os Arranjos Produtivos Locais: O caso de Nova Friburgo/RJ. 2006. Tese (Doutorado em Planejamento Urbano e Regional) - Instituto de pesquisa e planejamento urbano e regional, Universidade Federal do Rio de Janeiro, Rio de Janeiro, 2006.

BRITTO, J.; VARGAS, M.; CARVALHO, G. Políticas para Arranjos Produtivos Locais no Estado do Rio de Janeiro: Aspectos conceituais, institucionalidade e perspectivas de desenvolvimento. In.: CAMPOS, R.; STALliVIERI, F.; VARGAS, M.; MATOS, M. (orgs.). Políticas estaduais para Arranjos Produtivos Locais no Sul, Sudeste e Centro-Oeste do Brasil. Rio de Janeiro: E-Papers, 2010.

CAMPOS, R.; STALliVIERI, F.; VARGAS, M.; MATOS, M. (orgs) Políticas Estaduais para Arranjos Produtivos Locais no Sul, Sudeste e Centro-Oeste do Brasil. Rio de Janeiro: E-Papers, 2010.

CARLSSON, B.; STANKIEWICZ, R. On the Nature Function and Composition of Technological Systems. Journal of Evolutionary Economics, v. 1, n. 2, p. 93-118, 1991.

CARVAlHO, G. Análise e mapeamento dos Arranjos Produtivos Locais do Estado do Rio de Janeiro. 2010. Dissertação (Mestrado em Economia) - Programa de pós-graduação em economia, Universidade Federal Fluminense, Niterói, 2010.

CASSIOLATO, J.; LASTRES, H. (orgs.). Globalização e inovação localizada: experiências de sistemas locais no Mercosul. Brasília: IBICT, 1999.

Sistema de Inovação e Desenvolvimento: as implicações de política. São Paulo em Perspectiva, São Paulo, v. 19, n. 1, p. 34-45, 2005.

CASSIOLATO, J.; MATOS, M. Política Brasileira para Arranjos Produtivos Locais: o Aprendizado Acumulado e suas Perspectivas. In.: LASTRES, H.; PIETROBELI, C.; CAPORALI, R.; SOARES, M.; MATOS, M. (orgs.). A Nova Geração de Políticas de Desenvolvimento Produtivo: Sustentabilidade Social e Ambiental. Brasília: CNI, 2012.

CASTRO, R. S. Resistência e colaboração na reestruturação produtiva: uma análise das operárias costureiras de Nova Friburgo/RJ. 2011. Dissertação (Mestrado em Ciências Sociais) - Faculdade de ciências e letras, Universidade Estadual Paulista, Marília/SP, 2011.

EPSZTEJN, R.; REGAZZI, R. Proposta de Modelo Teórico de Cluster de pequenas e médias empresas para o polo de confecções e moda íntima da Região de Nova Friburgo - RJ. XXI Encontro Nacional de Engenharia de Produção, Salvador, 2001.

FAJNZYLBER, F. Competitividad internacional: evolución y lecciones. Revista de la CEPAL, n. 36, p. 7-24, 1988

\section{POLÊM!CA $\mid$ LABORE}

Polêmica - Revista Eletrônica da Uerj - Rua São Francisco Xavier, 524, $1^{\circ}$ andar bloco D, sl.1001 • Tels.: +55 21 2334-4088 / 4087 • http://www.e-publicacoes.uerj.br/index.php/polemica/index http://www.labore.uerj.br • laboreuerj@yahoo.com.br 
FGV - Fundação Getúlio Vargas. Potencialidades do Estado do Rio de Janeiro. Rio de Janeiro: FGV Editora, 1998.

FUMIN - Fundo Multilateral de Investimentos. Impact Evaluation of the Program for the Development of Industrial Districts in Brazil. Santiago: FUMIN, 2010.

GADELHA, C. Política Industrial: uma visão neo-schumpeteriana sistêmica e estrutural. Revista de Economia Política, São Paulo, v. 21, n. 4, p. 149-171, 2001.

GARCEZ, C.; KAPLAN, E.; MAGALHÃES, W.; LEMOS, C.; LASTRES, H. Análise de políticas para arranjos produtivos locais no Brasil: uma introdução. In.: CAMPOS, R.; STALLIVIERI, F.; VARGAS, M.; MATOS, M. (orgs.). Políticas Estaduais para Arranjos Produtivos Locais no Sul, Sudeste e Centro-Oeste do Brasil. Rio de Janeiro: E-Papers, 2010.

HASENCLEVER, L. Nova Friburgo: uma economia especializada e regional face aos mercados nacional e internacional. In: . (Org.). O Desenvolvimento Local no Estado do Rio de Janeiro. Rio de Janeiro: Epapers, 2005.

KLEVORICK, A. K.; LEVIN, R.; NELSON, R.; WINTER, S. On the sources and significance of inter-industry differences in technological opportunities. Research Policy, v. 24, n. 2, p. 185-205, 1995.

LA ROVERE, R.; HASENCLEVER, L.; MELO, L. M.; FIALHO, B.; SILVA, M. Industrialização Descentralizada: Sistemas Industriais Locais Estudo do Setor Têxtil e de Confecções. Relatório de Pesquisa. Rio de Janeiro. BNDES e FINEP, 2000.

LASTRES, H. M. M.; PIETROBELLI, C.; CAPORAli, R.; COUTO, M. C.; MATOS, M. (Orgs.) A nova geração de políticas de desenvolvimento produtivo: sustentabilidade social e ambiental. Brasília: CNI, 2012.

LEMOS, C. R.; ALBAGLI, S.; SZAPIRO, M. H. S. Promoção de Arranjos Produtivos Locais: Iniciativas em nível federal. Relatório de Pesquisa. Rio de Janeiro: RedeSist, 2004.

MATOS, M.; CASSIOLATO, J.; PEIXOTO, F. O Referencial conceitual e metodológico para a análise de Arranjos Produtivos Locais. In.: MATOS, M.; CASSIOLATO, J.; LASTRES, H.; GARCEZ, C.; SZAPIRO, M. (orgs.). Arranjos Produtivos Locais: Referencial, Experiências e Políticas em 20 anos da RedeSist. Rio de Janeiro: E-Papers, 2017.

RAFFESTIN, C. Por uma geografia do poder. São Paulo: Ática, 1993.

REGAZZI, R. D. Moda íntima de Nova Friburgo: Um arranjo produtivo que deu certo. Rio de Janeiro: SEBRAE/RJ, 2007.

SANTOS, M. Por uma outra globalização: do pensamento único à consciência universal. São Paulo: Record, 2000.

SEBRAE - Serviço Brasileiro de Apoio à Pequenas e Micro Empresas. Metodologia do Programa de Desenvolvimento de Distritos Industriais. Brasília: SEBRAE, 2002.

SEBRAE - Serviço Brasileiro de Apoio à Pequenas e Micro Empresas. Relatório Resumo do Programa de Desenvolvimento de Distritos Industriais: Projeto de APL de Moda Íntima de Nova Friburgo e Região. Nova Friburgo: SEBRAE, 2006.

Recebido em: 01/08/2018.

Aceito em: 30/09/2018.

\section{POLÊM!CA $\mid$ LABORE}

Polêmica - Revista Eletrônica da Uerj - Rua São Francisco Xavier, 524, $1^{\circ}$ andar bloco D, sl.1001 • Tels.: +55 21 2334-4088 / 4087 • http://www.e-publicacoes.uerj.br/index.php/polemica/index http://www.labore.uerj.br • laboreuerj@yahoo.com.br 